\title{
XV Reunión de jóvenes paleolitistas españoles
}

\author{
Francisco Javier Muñoz laáñez \\ Ángela Rosales Quintana
}

Durante los días 29 y 30 de abril y el día 1 de mayo de 1994 se celebró en la ciudad de Córdoba la XV Reunión de Jóvenes Paleolitistas Españoles. Las sesiones de trabajo tuvieron lugar en las Facultades de Filosofía y Letras y de Ciencias de la Universidad de Córdoba, bajo la coordinación de Beatriz Gavilán Ceballos y Rafael Baena Escudero. El título de la reunión fue: "El conocimiento de las Investigaciones Paleolíticas en la Península Ibérica, 15 años después, perspectivas de futuro".

A la reunión asistieron figuras ya consagradas en este campo de la Prehistoria como Jordi Estévez, Asunción Vila, María Ángeles Querol y Francisco Giles, junto a jóvenes investigadores que comenzamos en esta disciplina.

El día 29, por la tarde, se procedió a la presentación de todos y cada uno de los asistentes, en donde se intentó crear un clima de cordialidad para poder intercambiar experiencias y opiniones. Durante la presentación tuvimos constancia de la presencia entre nosotros de un "aficionado". Después de una agria discusión sobre su permanencia en la reunión y de una inmolación pública del "clandestino", la organización permitió, incomprensiblemente, la exposición de su comunicación.

La reunión fue inaugurada con la comunicación de María Ángeles Querol: «Enseñar Paleolítico», donde se presentó un pliego de descargos sobre las deficiencias de la enseñanza de Paleolítico en España, que tuvo como único responsable y culpable al estudiante.

La jornada se cerró con la comunicación de Jordi Serrallonga sobre la Etoprimatología comparada y su aplicación al estudio de la cultura material. Aquí se hizo un análisis de los útiles empleados por primates, sus distintos usos y la potencialidad que este tipo de estudios tienen en su aplicación al análisis de los ítems arqueológicos más antiguos. 
El día 30 se reanudaron las sesiones con la proyección del vídeo: «III Juegos Intercontinentales Prehistóricos", celebrados en Barcelona en junio de 1992, que sustituyó a la más que interesante comunicación: "Síntesis de los últimos quince años de investigaciones paleolíticas en España", de Jordi Estévez y Asunción Vila. A continuación, Manuel Luque presentó un programa de simulación tridimensional para la representación de distribuciones de restos arqueológicos, que acompañó con ejemplos experimentales como posibles modelos para contrastarlos con casos reales. También habló de un interesante estudio que está realizando sobre los cantos tallados del yacimiento de Le Vallonet (Francia) para intentar discriminar fracturas antrópicas de fracturas naturales.

Nuevamente, la comunicación de Asunción Vila y Jordi Estévez: "Análisis funcional de la industria lítica" fue sustituida por una análisis de los principales problemas y enfermedades que afectan a la investigación prehistórica, siendo los males más significativos analizados:

- El "más difícil todavía" (el hallazgo de hominido más antiguo, la industria lítica más espectacular, etc.).

- La "umbilicultura", que afecta a nuestros investigadores (todo prehistoriador piensa siempre que el yacimiento en el que él trabaja es el más importante para el período histórico que investiga).

- Y otros ...

Seguidamente, Juan Rodríguez, Ramón López y Francisco J. Muñoz presentaron una ficha para el estudio de la industria lítica no reelaborada, que se está aplicando al material de superficie del yacimiento Pedazo del Muerto (Pinto, Madrid), y que tiene como objetivos principales el estudio de la calidad de la materia prima empleada, las alteraciones antrópicas y naturales en el material arqueológico y un análisis tecnológico del mismo. El resto del día se dedicó a la presentación de nuevos yacimientos y a la ampliación de los datos que han aportado las excavaciones de otros ya conocidos. La mayor parte de las comunicaciones se centraron en Andalucia (Córdoba, Cádiz y Almería), con interesantes sistematizaciones de los datos obtenidos hasta el momento y planteamientos de futuras líneas de actuación.

Destacamos la comunicación de Beatriz Gavilán Ceballos y Juan Carlos Vera Rodríguez, que bajo el título «Primeros datos para el conocimiento del Paleolítico Medio en el Subbético cordobés", recogía los datos obtenidos en la Cueva del Ángel (Lucena, Córdoba) y Cueva de los Murciélagos (Zuheros, Córdoba), información que aportaba novedades importantes para establecer una secuencia cronológica del Paleolítico Medio en la Subbética cordobesa. 
Otras conferencias de interés fueron las de Arantxa Soriano Alonso: "Localizaciones Paleolíticas en la campiña de Córdoba», Francisco Giles y otros: "Estado actual de las investigaciones paleolíticas en la provincia de Cádiz», y Sergio Ripoll: «El yacimiento solutrense de La Cueva de Ambrosio (Vélez Blanco, Almería)». A la completa secuencia que presenta este yacimiento para el conocimiento del Solutrense, hay que añadir el hallazgo de arte rupestre (pintura y grabado) asociado a los niveles arqueológicos, y nuevos hallazgos de arte mueble sobre plaqueta. Asimismo, Jesús García y José Antonio Faro presentaron un estado de la cuestión del Paleolítico Inferior en Navarra, con la aportación de nuevos datos, y Josep Casabó y otros un proyecto de investigación sobre los últimos cazadores-recolectores del Paleolítico Superior (Val d'Uxó, Castellón).

Después de cada comunicación se intentó entablar un diálogo en donde se contestaran las preguntas de los asistentes y en donde se realizaran reflexiones en voz alta. Sin embargo, todo esto fue imposible por la actitud de unos pocos - aunque significativos- asistentes a la reunión, que sistemáticamente cuestionaban la utilidad de las aportaciones presentadas.

Si bien, el objetivo primordial de la reunión era analizar el desarrollo de la investigación del Paleolítico en nuestro país en los últimos quince años; la mayor parte de las intervenciones estuvieron centradas en la cuestionada validez de los yacimientos en posición secundaria y la importancia evidente de los yacimientos en posición primaria. No obstante, frente a la clara rentabilidad científica de estos últimos, no puede obviarse la información, en ocasiones de demostrada utilidad, que nos aportan los estudios desarrollados en yacimientos en posición secundaria. Por ello, no compartimos las críticas que se dirigieron hacia los trabajos realizados por jóvenes investigadores, que han iniciado su trayectoria profesional en este tipo de yacimientos.

La reunión fue clausurada el día 1 con una jornada de campo, en la que se visitó las terrazas del río Genil en su tramo bajo (Palma del Río). La visita contó con un magnífico dosier de apoyo, elaborado por Rafael Baena Escudero y Francisco Araque Aranda con el título de "Evolución cuaternaria del río Genil: valoración geomorfológica y problemática de las localizaciones paleolíticas en conexión de su tramo bajo (Córdoba)».

Por último, se acordó que la próxima Reunión de Paleolitistas Españoles se celebrará el próximo año en la ciudad de Pamplona (Navarra). 